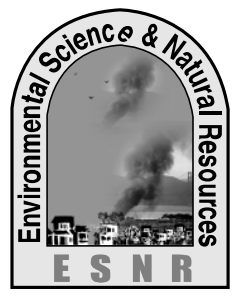

J. Environ. Sci. \& Natural Resources, 6(1): 01 -06, 2013

ISSN 1999-7361

\title{
Diurnal Pattern of Energy Fluxes Over Rice Field
}

\author{
${ }^{1}$ A. A. Mahmud, ${ }^{1}$ M. A. Baten, ${ }^{1}$ M. B. Khan and A. Miyata ${ }^{2}$ \\ ${ }^{1}$ Department of Environmental Science, Bangladesh Agricultural University, Mymensingh \\ ${ }^{2}$ National Institute of Agro-Environmental Science,Tsukuba, Japan
}

\begin{abstract}
An experiment was conducted to investigate the factors responsible for the partitioning of energy balance components over BRRI dhan 28 (Boro season) rice crop at the paddy field of Bangladesh Agricultural University Farmland, Mymensingh during August 2010 to July 2011. The whole measurement period was divided into two seasons such as Boro rice and Post Boro fellow. Energy balance components were measured in this experiment using sophisticated sensors. The cropping season differences in water and energy fluxes were attributed by the availability of sunlight and abundance of water at the site as well as differences in sunshine hours during winter. Irrigation during winter Boro had substantial influence on the seasonal and interannually variability of energy partitioning at rice field. Of the papers diurnal variations in energy balance components are shown and variations in the energy balance components are discussed.
\end{abstract}

Key Words: Fluxes, Solar Energy

\section{Introduction}

Evaluation of energy balance components is very important to facilitate yield increase in different field crops (Chin Choy and Kanemasu, 1974). Because it is a convenient way of comparing the micrometeorology of the relative magnitudes of the energy balance component of different plant communities (Denmead, 1969). With this view, different works on the measurements of these components had already been done in different parts of the world with varying geographical distributions (Brown and Schrader, 1959; Musick and Grimes, 1961; Stickler, 1964). The energy balance shows how the net available solar energy from the sun is partitioned into different components for the purpose of transpiration, evapotranspiration, advective energy movement and ground heat storage. There are essentially four types of energy fluxes at an ideal surface, namely the net radiation to or from the surface, the sensible (direct) and latent (indirect) heat fluxes to or from the atmosphere, and the heat flux into or out of the sub medium (soil or water) (Arya, 2001). The net radiative flux is a result of radiation balance at the surface. During the daytime it is usually dominated by the solar radiation and is almost always directed towards the surface, while at night the net radiation is much weaker and directed away from the surface. As a result, the surface warms up during the day time, while it cools during the evening and night hours under clean sky (Arya, 2001). The direct or sensible heat flux at and above the surface arises as a result of the difference in the temperatures of the surface and the above. Actually, the temperature in the atmospheric surface layer varies continuously with height, with the magnitude of the vertical temperature gradient usually decreasing with height. The sensible heat flux is usually directed away from the surface during the daytime hours, when the surface is warmer than the air above, and vice versa during the evening and nighttime periods. Thus, the heat flux is down the average temperature gradient (Arya, 2001). The latent heat or water vapor flux is a result of evaporation, evapotranspiration, or condensation at the surface and is given by the product of the latent heat of evaporation or condensation and the rate of evaporation or condensation. The water vapor transfer through air does not involve any real heat exchange, except where phase changes between liquid water and vapor actually take place. Nevertheless, evaporation results in some cooling of the surface, which in the surface energy budget is represented by the latent heat flux from the surface to the above (Arya, 2001). The heat exchange through the ground medium is primarily due to conduction if the medium is soil, rock, or concrete. During the daytime, the surface receives radiative energy, which is partitioned into sensible and latent heat fluxes to the atmosphere and the heat flux to the sub medium. In Bangladesh rice is grown under diverse ecological situation in three seasons namely Aus, Aman and Boro. Considering above views in mind, the present study was, therefore, undertaken with the following objectives:

I. To measure the diurnal and seasonal pattern of energy partitioning over rice fields

II. To investigate the factors those affect the partitioning of solar energy over rice field

\section{Materials and Methods}

\section{Description of the Site}

The study site, called MYM (three letter international code name for Asia Flux) is located in the paddy field of Bangladesh Agricultural University Farmland $\left(24.75^{\circ} \mathrm{N}, 90.5^{\circ} \mathrm{E}, 18 \mathrm{~m}\right.$ above sea level), $6 \mathrm{~km}$ to the south of Mymensingh town and $115 \mathrm{~km}$ to the north of Dhaka, the capital city of Bangladesh (Fig.1). 
Magnetic Declination: $-00^{\circ} 20^{\prime}$ (negative west), 0.0'/year (2006/1/1); -00 24', 0.0'/year (2010/12/31) (NOAANGDC:http://www.ngdc.noaa.gov/geomagmo dels/struts/calcDeclination). This extensive field (about $78.28 \mathrm{ha}$ ) is used only for rice cultivation for a period of about 40 years. A weather yard and irrigation station and located near the study site. The usual cropping patterns are irrigated Boro riceFallow-rain fed Aman rice.

\section{Crop}

For this experiment, BRRI dhan 49 was used for Aman season and BRRI dhan 28 was used for Boro season.

\section{Soil}

MYM site soils are dark-gray non-calcareous floodplain type (UNDP and FAO, 1988). Study site soil possesses silty loam texture and low contents of organic matter. Topography of the soil at MYM site was low with fairly leveled surface.

Micrometeorological instrumentation

Table 1. Measurement of meteorology at MYM site

\begin{tabular}{|c|c|c|}
\hline Observation items & Levels/depth/height & Instrument \\
\hline $\begin{array}{l}\text { Incoming and outgoing short- } \\
\text { wave radiation }\end{array}$ & $3.0 \mathrm{~m}$ & $\begin{array}{l}\text { Four component net radiometer (MR-40, Eko, Tokyo, Japan) } \\
\text { Four Component Radiometer (MR-40, Eko) }\end{array}$ \\
\hline $\begin{array}{l}\text { Incoming and outgoing long-wave } \\
\text { radiation }\end{array}$ & $3.0 \mathrm{~m}$ & Four Component Radiometer (MR-40, Eko) \\
\hline Net radiation & $3.0 \mathrm{~m}$ & Quantum sensor (LI-190, LI-COR) \\
\hline Incoming and outgoing PPFD & $2.95 \mathrm{~m}$ & \\
\hline Transmitted PPFD & & Quantum sensor (LI-191, LI-COR) \\
\hline Incoming short-wave radiation & Below canopy & Pyranometer (MS-62, Eko) ${ }^{1)}$ \\
\hline Air temperature & $3.0 \mathrm{~m}$ & \\
\hline Relative humidity & & Humicap (HMP45A, Vaisala, Finland) \\
\hline \multirow[t]{2}{*}{ Soil temperature } & $1.65,2.95 \mathrm{~m}$ & Humicap (HMP45A, Vaisala, Finland) \\
\hline & $1.65,2.95 \mathrm{~m}$ & Type-T thermocouple \\
\hline Soil heat flux & $0,0.05,0.1,0.2,0.4 \mathrm{~m}$ (five points) & \\
\hline \multirow[t]{2}{*}{ Soil water content } & $0.05 \mathrm{~m}$ (three points) & Heat flux plate (MF-180M, Eko) \\
\hline & $0.05 \mathrm{~m}$ (three points), & TDR (TDR100, Campbell Scientific, USA) ${ }^{2)}$ \\
\hline \multirow[t]{2}{*}{ Field water level } & $0.1,0.2,0.3 \mathrm{~m}$ & \\
\hline & Two points & Capacitive water depth probe (model 6521 , Unidata, Australia) \\
\hline Water temperature & $0.02,0.05 \mathrm{~m}$ & Type-T thermocouple \\
\hline Barometric pressure & - & Silicon capacitive pressure sensor (PTB210, Vaisala) \\
\hline Precipitation & - & Tipping bucket rain gauge (Texas Instruments) \\
\hline
\end{tabular}

\section{Management practices}

The experimental crops of rice were grown under recommended cultural practices at MYM site under the active supervision of Central Farm Authority at Bangladesh Agricultural University. This experiment was conducted without any influence what so ever on the rice paddy ecosystem to measure the status of energy balance.

\section{Flux Measurement Systems Micrometeorological measurement}

Micrometeorological parameters are very important in respect of plant physiological activity and growth where it substantially influences the energy exchange

\section{Climate}

In Mymensingh, both the summer and winter are relatively mild. The maximum and minimum temperatures as observed in April and January range between $33^{\circ} \mathrm{C}$ and $12^{\circ} \mathrm{C}$. Annual mean air temperature is 25.4 degree Celsius (1995-2008). Rainfall starts in May and continues up to September. Ninety-five per cent of the annual rainfall occurs during the monsoon. Annual precipitation: 2,252mm (1995-2008). Annual rainfall recorded in 1996 was 1620 millimeters. The highest humidity observed from July to September is around $94 \%$ and minimum is about $49 \%$ from January to April (BBS, 1998). MYM site annual mean temperature and totalized rainfall data were also collected for the past 14 years from Weather Yard, BAU, Mymensingh. Mymensingh seems to be less affected by natural calamities like flood, cyclone or drought as compared to other districts of the country.
Tipping bucket rain gauge (Texas Instruments)

from rice paddy fields. Therefore, all state-of-the-art micrometeorological sensors were installed in a mast. These supporting data were sampled every 5 seconds using a CR23X data loggers supported by an AM25T multiplexer. Instruments used in micrometeorological measurement are presented in Table 1. Program used for collecting meteorological data.

Data are sampled and recorded using CR23X (Campbell) unless specified below.

1. A battery-driven data logger (KADEC-UP, Sapporo, Japan) is used for sampling and storage of pyranometer data 
2. CR10X (Campbell) is used for a sampling and storage of TDR data.

\section{Calibration}

Every year instruments were calibrated with standard sensors specially the PAR sensors those are generally more affected due to long-term exposure at the site.

\section{Data Collection and Mathematical Interpolation}

Data were collected intermittently mainly on the microclimatic parameters and plant attributes at different days after sowing and mathematically interpolated for additional analysis.

\section{Energy Balance}

The energy balance was computed from the following equation

$R_{n} \downarrow+H \uparrow+l E \uparrow+G \downarrow=0$

Where, $R_{n}=$ canopy net radiation, $H=$ sensible heat flux, $l E=$ latent heat of vaporization and $G=$ ground heat flux, all with units of $\mathrm{Wm}^{-2}$. In the above stated equation, fluxes of $R_{n}$ and $G$ towards the surface were positive and towards the atmosphere were negative, while fluxes of $H$ and $l E$ towards the atmosphere were positive and vice-versa. The above equation can be rearranged as

$R_{n} \downarrow=H \uparrow+l E \uparrow+G \downarrow$

$R_{n} \downarrow-G \downarrow=H \uparrow+l E \uparrow$

\section{Mathematical Interpolation}

The energy balance of a crop canopy can be calculated by using Bowen Ratio Energy Balance (BREB) Method. The Bowen ratio $(\beta)$ is the ratio of the sensible and latent heat fluxes above the surface (Bowen, 1926).

$$
\text { Bowen Ratio }(\beta)=\mathrm{Q}_{\mathrm{H}} / \mathrm{Q}_{\mathrm{E}}=\gamma\left(\Delta \mathrm{T}_{\mathrm{a}} / \Delta \mathrm{e}_{\mathrm{a}}\right)
$$

Where, $\gamma$ is the psychometric constant $\left(65 \mathrm{~Pa} \mathrm{~K}^{-1}\right), \mathrm{T}_{\mathrm{a}}$ is air temperature $(\mathrm{K})$, and $\mathrm{e}_{\mathrm{a}}$ is atmospheric vapor pressure $(\mathrm{Pa})$. When $\beta>1$, more energy is directed from the surface as sensible heat than as latent heat. In contrast, when $\beta<1$, the latent flux is the primary pathway for convective heat loss. Wet surfaces have a lower $\mathrm{b}$ than dry surfaces. $\left(\Delta \mathrm{T}=\mathrm{T}_{1}-\mathrm{T}_{2}\right.$, Where $\mathrm{T}_{1}$ is the upper temperature and $\mathrm{T}_{2}$ is the down temperature; $\Delta \mathrm{e}=\mathrm{e}_{1}-\mathrm{e}_{2}$, where $\mathrm{e}_{1}$ is the upper atmospheric vapor pressure and $e_{2}$ is down atmospheric vapor pressure)

\section{Sensible Heat Flux}

From Bowen Ratio Energy Balance $H$ (sensible hat flux) can be calculated by using the following formula:

$$
H=\frac{R_{n}-G}{1+\beta^{-1}}
$$

\section{Latent Heat Flux}

From Bowen Ratio Energy Balance $l E$ (latent heat flux) can be calculated by using the following formula:

$$
l E=\frac{R_{n}-G}{1+\beta}
$$

\section{Ground Heat Flux}

The ground heat flux of the experimental plot was obtained directly from the Data logger output by using ground heat flow plates (EKO, MF-81). The sensors gave the flux data in $\mathrm{mV}$ and it was then converted using the sensitivity data provided by the manufacturer. But the sensor sensitivities were further calibrated with standard sensors by NIAES (National Institute of Agro Environmental Science). The data from these three ground heat flux plates were then converted into $\mathrm{Wm}^{-2}$ and averaged to obtain the appropriate ground heat flux of the maize-soybean intercrop.

\section{Data Retrieval and Analysis}

The data received at 10 second intervals from the sensors on different micrometeorological parameters from the experimental site were primarily recorded by CR23X Data logger (Campbell Scientifics, USA). Then the output data from the Data logger as $30 \mathrm{~min}$ average was stored in a storage module (SM4M, Campbell Scientifics, USA). The experimental raw data at $30 \mathrm{~min}$ intervals were retrieved from the storage module periodically for further averaging and mathematical interpolation. After obtaining $30 \mathrm{~min}$ average raw data from the field, these were then averaged again for $30 \mathrm{~min}$ intervals by using the program in Microsoft Excel. Data analyses were performed using MS Excel. Graphs were also prepared by the above mentioned software. As this kind of experiment only stresses on the monitoring of the climatic variables no replication possible and trends are obtained with average data streams those were collected during the intended span of this experiment. Since the initial data were recorded as 10 sec intervals which were $30 \mathrm{~min}$ averaged, so statistical errors were too minimum and hence neglected.

\section{Results and Discussion}

The experiment was carried out from August 2010 to July 2011 over two rice growing seasons (Aman season 2010 and Boro season 1011) and the post fallow periods (Post Aman Fallow 2010 and Post Boro Fallow 2011). During the experimental periods observations were made on thirty clear days. The observations include Energy Balance Bowen-ratio measurements system (net radiation, soil heat flux, 
temperature and vapor pressure gradient), relative humidity, wine speed and solar radiation.

\section{Diurnal energy balance pattern of rice field}

Diurnal patterns of energy balance components over rice field of Aman 2010 (early growth stage, full growth stage and ripening stage), post Aman fallow, Boro 2011 (early growth stage, full growth stage and ripening stage) and post Boro fallow are presented in Figure 1 to 8 respectively. Sensible heat flux $(H)$ and latent heat flux $(l E)$ followed the pattern of global radiation throughout the day. In the rice field latent heat flux $(l E)$ was the governing form of water loss and consumed most of the energy of the net radiation $(R n)$. The sensible heat $(H)$ in the rice field showed a slight fluctuations indicating that the vegetative and bare fields acted as a factor for heat transfer towards the atmosphere. During the daytime the ground heat flux $(G)$ was positive signifying that the soil absorbed heat from the atmosphere.

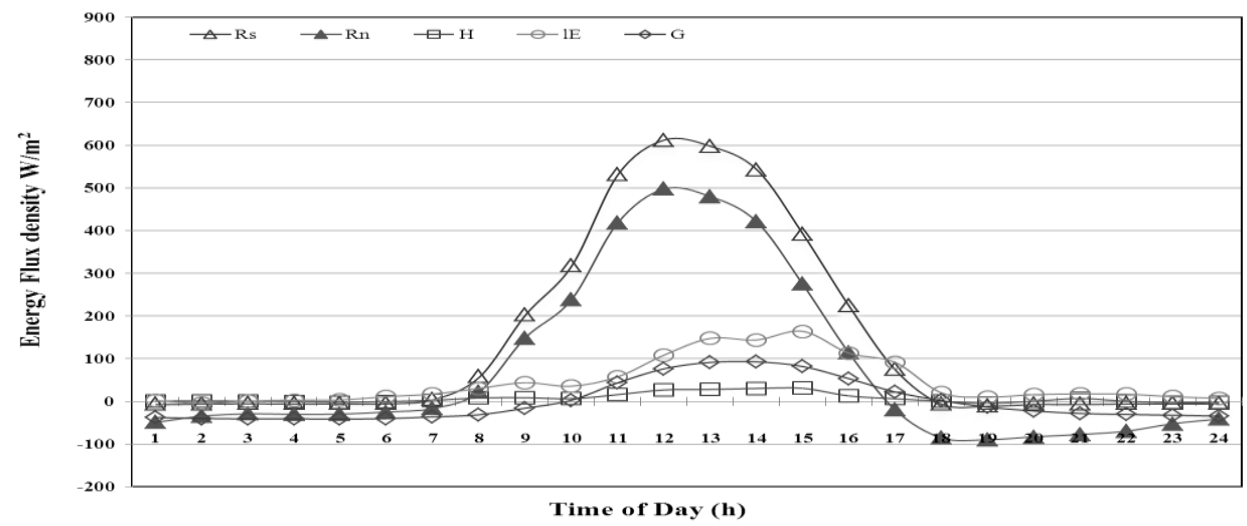

Fig. 1. Diurnal patterns of energy balance of early growth stage of Boro rice field (21January 2011).

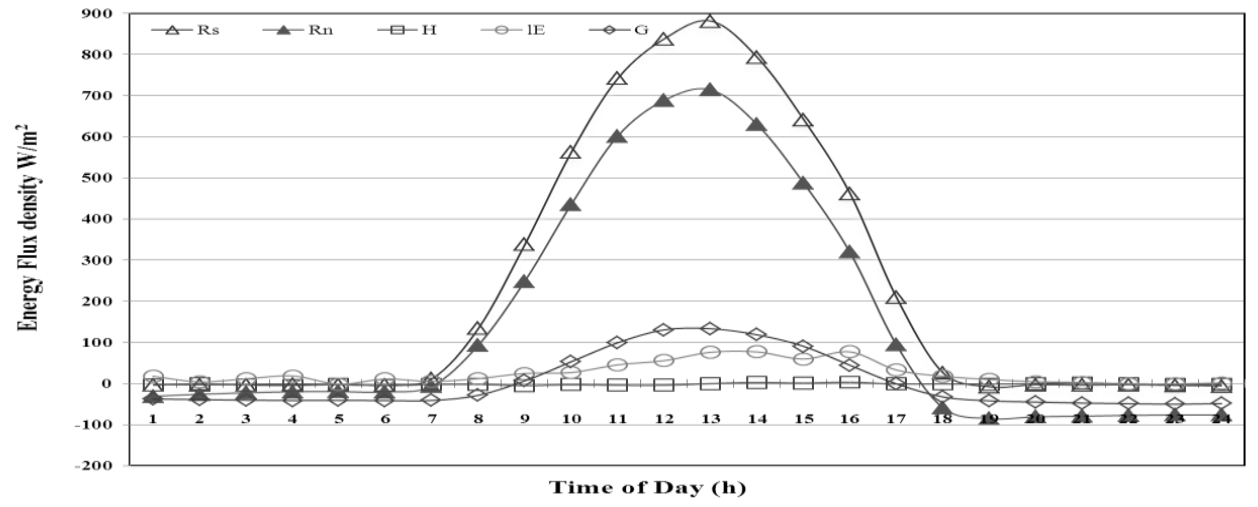

Fig. 2. Diurnal patterns of energy balance of full growth stage of Boro rice field (22 February 2011).

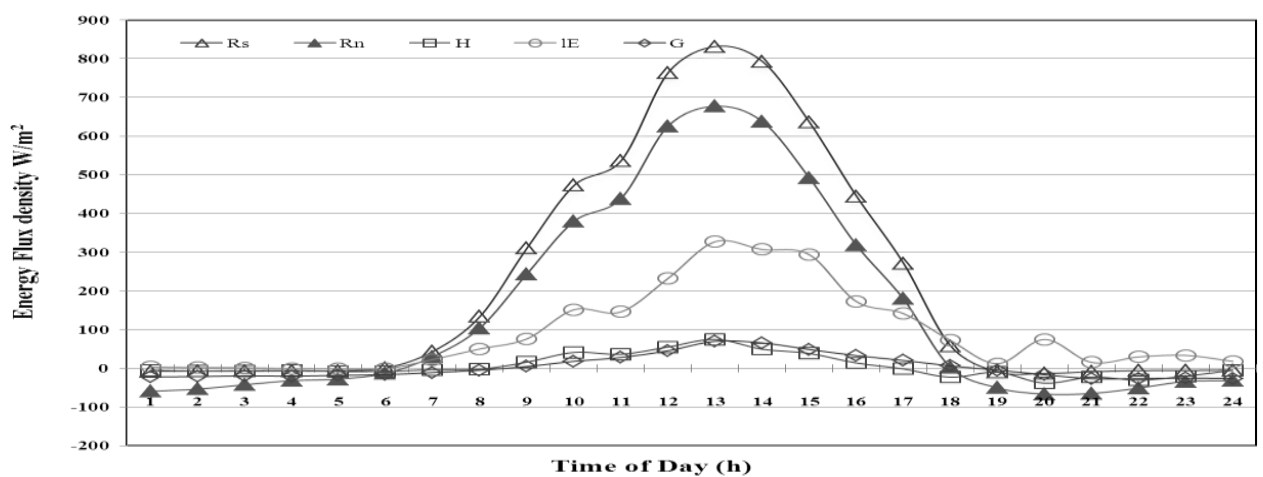

Fig. 3. Diurnal patterns of energy balance of ripening stage of Boro rice field (21 April 2011). 


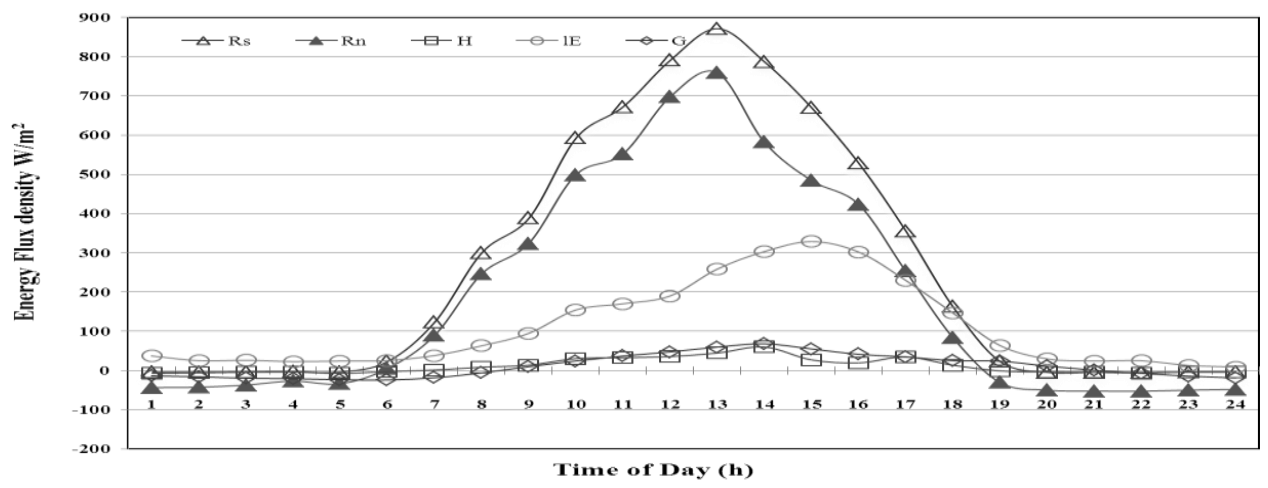

Fig. 4. Diurnal patterns of energy balance of post Boro fallow rice field (03 June 2011).

\section{Daily pattern of energy partitioning}

The energy partitioning was primarily controlled by the amount of surface vegetation and soil moisture conditions. This was best seen during the rice growing season Aman 2010 and Boro2011. During growing season the soil and canopy experienced a shift form dry to wet due to irrigation or rain events. Due to irrigation or rain input soil moisture increase, $l E$ dominated the daytime energy partitioning (Fig.1 to Fig.3). At night $G$ was overwhelmingly dominant. $\mathrm{G}$ was also positive during day time but the amount was considerably low due to the presence of thick rice canopy. Water level did not significantly affect the fraction of $R n$ partitioned into $G$ for either the growing periods, but considerably affected $\mathrm{H}$ and $\mathrm{lE}$ fractions as represented by their midday values.

In the growing season $H$ and $l E$ became relatively similar, $l E$ increased during the first half of the day up to $15: 00 \mathrm{~h}$ and decreased on the second half. In contrast, $\mathrm{H}$ also increased during the first half up to 15:00h and decreased at the late hours of the day. The amount of $H$ was more than $l E$ from 13:00h to 18:00h. But both of them followed the pattern of global radiation and produced small values during early and late hours and peak values at mid hours of the day. It might be the affected by the unexpected rainfall or fog. The non-limiting water in the soil increased transpiration in the rice canopy and evapotranspiration from the soil surface simultaneously. The combined effect might have increased the $l E$ of the canopy. Marked decrease in $G$ may be resulted from greater surface cooling by evaporation. Diurnal patterns of the rice field were comparatively similar but they only varied in magnitude while the rice field kept fallow (Fig.4 and fig.4).

\section{Acknowledgements}

The authors deeply acknowledge the National Institute for Agro-Environmental Sciences (NIAES),
Tsukuba, Japan; Japan Society for the Promotion of Science (JSPS) and University Grants Commission of Bangladesh (UGC), Dhaka and Bangladesh Agricultural University Research System (BAURES), Bangladesh Agricultural University, Mymensingh for providing financial support and research facilities for conducting the entire research work with utmost cooperation.

\section{References}

Arya, P. S. 2001. Introduction to Micrometeorology. Second Edition. Academic Press. A Harcourt Science and Technology Company, Harcourt place, 32 Jamestown Road, London NWI 7BY, UK. pp.11-13.

Baldocchi, D. D.; Xu, L. K. and Kiang, N. 2004. How plant functional-type, weather, seasonal drought, and soil physical properties alter water and energy fluxes of an oak-grass savanna and an annual grassland. Agric. For. Meteorol., 123:13-39.

Bangladesh Bureau of Statistics. 2010. Summary Crop Statistics-Area, Yield Rates and Productions of Major Crops 2007-2008, 2008-2009 and 2009-2010. Online: 10.09.2011.Availablefrom:http://www.bbs.g ov.bd/WebTestApplication/userfiles/Image/ AgricultureCensus/All_Crops_summary_0910.pdf.

Brown, P. L. and Schrader, W. D. 1959. Grain yields, evapotranspiration and water use efficiency of grin gorghum under different cultural practices. Agron. J., pp. 339-343.

Chin Choy, E. W. and Kanemasu, E. T. 1974. Energy balance comparisons of wide and narrow row spacings in sorghum. Agron. J., 66: 98100. 
Denmead, O. T. 1969.Comparative micrometeorology of a wheat field and aforest of Pinus radiate. J. agril. Meteorol., p 358.

Geiger, R. 1980. Heat budget over the earth's budget surface: as the basis of micrometeorology. In. the climate near the ground. Harvard University Press. pp. 5-43.

Jones, G. H. 1994. Radiation in Plants and Microclimate. A quantitative approach to environmental plant physiology. Second edition. Cambridge University press, p. 428.

Kler, D. S.; Kaur, H. and Singh, S. 1992. Effect of biodirectional sowing and nitrogen on microclimate of indian rape ( Brassica campestris L.var.). Tori Environmental and Ecology., 10(2): 282-292.

Kondoh, A. and Higuchi, A. 2001. Relationship between satellite-derived spectral brightness and evapotranspiration from a grassland. Hydrological Process., 15:1761-1770.

Li, S. G.; Eugster, W. Asanuma, J.; Kotani, A.; Davaa, G.; Oyunbaatar, D. and Sugita, M. 2006. Energy partitioning and its biophysical controls above a grazing steppe in central Mongolia. Agricultural and Forest Meteorology., 137;89-106.

Musick, J. T. and Grimes, D. W. 1961. Water management and consumptive use by irrigated grain sorghum in western Kansan. Kans. Agr. Exp. Sta. Tech. Bull., p. 113.

Steduto, P and Hsiao, T. C. 1998. Maize canopies under two soil water regimes: II. Seasonal trends of evapotranspiration, carbon dioxide assimilation and canopy conductance, and as related to leaf area index. Agriculture and Forest Meteorology., 89: 185-200.

Stickler, F. C. 1964. Grain sorghum yields from 20 and 40 inch rows at various sand densities in Kansas. Kans. Agr. Exp. Sta. Tech. Bull., p. 474.

UNDP (United Nations Development Program) and FAO (Food and Agriculture Organization), 1998. Land Resources Appraisal of Bangladesh for Agricultural Development. Report 2. Agro-ecological Regions of Bangladesh. UNDP, FAO, Rome. pp116. 